\title{
Scenery Picture Memory Test: A new type of quick and effective screening test to detect early stage Alzheimer's disease patients
}

\author{
Hajime Takechi ${ }^{1}$ and Hiroko H Dodge $e^{2,3}$ \\ ${ }^{1}$ Department of Geriatric Medicine, Graduate School of Medicine, Kyoto University, Kyoto, Japan; \\ ${ }^{2}$ Department of Neurology, Oregon Health \& Science University, Portland, Oregon, and ${ }^{3}$ Institute for \\ Social Research, University of Michigan, Ann Arbor, Michigan, USA
}

\begin{abstract}
Aim: It is highly desirable to develop a neuropsychological screening test which is sensitive to the early stage of Alzheimer's disease (AD), and is easy to administer at the primary care physician's (PCP's) office.

Methods: Participants were $128 \mathrm{AD}$ patients and 54 healthy volunteers. Brief cognitive screening tests were administered to the participants including the Mini-Mental State Examination (MMSE), Clock Drawing Test (CDT), Verbal Fluency Test (VFT), a Verbal Category Cued Memory test (CCMT) and the Scenery Picture Memory Test (SPMT). In the SPMT, a scenery picture of a living room containing 23 familiar objects was used. The administration of the SPMT comprised the first shallow memory session (Pict 1) and the second deep memory session (Pict 2). The area under the receiver-operator curve (AUC) was used to compare the efficacy of SPMT with other cognitive tests.

Results: Pict 1, which requires less than 2 min to complete, had the same AUC as Pict 2, and showed significantly larger AUC than MMSE, CDT and VFT for all (MMSE 19-23) and very mild (MMSE $\geq 24$ ) AD patients. When we conducted the similar analysis separately for those younger than 75 years and those aged 75 years or older, we obtained the same results as above among the older age group. Pict 1 showed larger AUC than CCMT in overall sample and also in the older age group, although the difference was not statistically significant.
\end{abstract}

Conclusion: The SPMT could be useful for detection of mild and very mild AD in settings even where time is limited. Geriatr Gerontol Int 2010; 10: 183-190.

Keywords: dementia, picture superiority, primary care physician, screening test, visual memory.

Accepted for publication 1 October 2009.

Correspondence: Dr Hajime Takechi MD PhD, Department of Geriatric Medicine, Graduate School of Medicine, Kyoto University, 54 Shogoin Kawahara-cho, Sakyo-ku, Kyoto 606-8507, Japan. Email: takechi@kuhp.kyoto-u.ac.jp

Author contributions: H. T. designed the study, collected data and drafted the manuscript; H. D. contributed to data analysis and made critical revisions to the manuscript.

\section{Introduction}

As the population ages, the number of those afflicted with $\mathrm{AD}$ is expected to increase sharply. Early detection of $\mathrm{AD}$ is important for disease management but it is often difficult to distinguish early AD from normal cognitive aging. Early diagnosis is a particular challenge in the primary care setting where there is a lack of time and specialized expertise. ${ }^{1-3}$ 
It is generally agreed that those with early AD show memory decline greater than that expected for their age group. ${ }^{4}$ Changes in cognitive test performance can be powerful diagnostic tools, if neuropsychological assessment could be included in the clinical diagnosis of $\mathrm{AD}$. However, the majority of the familiar cognitive tests are not ideal for detecting early AD; some are too difficult, even for the healthy elderly (floor effect), while others are too easy for patients with early $\mathrm{AD}$ (ceiling effect). Tests developed to overcome these shortfalls include memory tests which provide cues during both the encoding and retrieval period, ${ }^{5-8}$ and show reasonably high sensitivity and specificity in distinguishing early $\mathrm{AD}$ from normal aging. These tests are, however, timeconsuming and their administration requires expertise not available in all primary care physician (PCP) offices. Further, older adults are sometimes reluctant to take long and effortful tests.

Visual memory is a key component of everyday life and healthy elderly have a relatively large capacity for memory for visual information encountered in daily life even without active conscious effort. ${ }^{9-12}$ Because a central feature of $\mathrm{AD}$ is the decline in episodic memory, ${ }^{13}$ several well-established visual memory tests, such as the Benton Visual Retention Test and the ReyOsterrieth complex figure, can be used to assess nonverbal memory. ${ }^{14,15}$ However, the abstract figures to be encoded and retrieved in these tests do not reflect daily life and both tests suffer from floor effects among the elderly. The third edition of the Wechsler Memory Scale (WMS-III) introduced the Family Pictures subtest which was designed to assess recall for scene characters, character activity and character location. This test uses non-abstract figures combined with verbal answers. ${ }^{16}$ However, the test is time-consuming and complex in scoring, and has been used primarily to study cognition in schizophrenia or temporal epilepsy. ${ }^{17,18}$ In the current study, we developed a new type of short and simple memory test assessing visual memory encoded as scenery, combined with verbal answers, to be used to detect mild AD.

\section{Methods}

\section{Participants}

The patients in the $\mathrm{AD}$ group came from outpatient referrals to the memory clinic of the Department of Geriatrics in Kyoto University Hospital. All patients underwent brain computed tomography or magnetic resonance imaging as well as a battery of laboratory tests including thyroid function, vitamin B12, folate and serum calcium concentration. A diagnosis of $\mathrm{AD}$ was made according to the fourth edition of the Diagnostic and Statistical Manual of Mental Disorders (DSM-IV) criteria and the National Institute of Neurological and
Communicative Disorders and Stroke-Alzheimer's Disease and Related Disorders Association (NINCDSADRDA) criteria. ${ }^{19,20}$ We defined mild and very mild AD according to operational criteria using Mini-Mental State Examination (MMSE) scores: ${ }^{21} 19-23$, mild; and 24 and over, very mild. Of the 128 individuals with $\mathrm{AD}$, 44 were classified as mild $\mathrm{AD}$ and 84 very mild $\mathrm{AD}$ by this criterion. Those with MMSE scores below 19 were excluded from the current analysis. Separately, 39 consecutive patients attending the memory clinic were recruited to test reliability, regardless of dementia diagnosis or subtype; $14 \mathrm{AD}$ patients and three non-AD patients (two vascular dementia, one Fahr disease) for assessing inter-rater reliability, and $16 \mathrm{AD}$ patients and six non-AD patients (three vascular dementia, one frontotemporal dementia, one depression, one delusion) for assessing test-retest reliability.

Fifty-four healthy volunteers with a Clinical Dementia Rating (CDR) of 0 were recruited from two sources: community-dwelling elderly who belonged to the Sakyo Geriatric Welfare Center, and outpatients in the Department of Geriatrics in Kyoto University Hospital. The inclusion criteria also included being free from depression, cerebral vascular disease, cerebral vascular accident or any other psychological disorder. This study was carried out according to the ethical guidelines for biomedical research involving human subjects set by Kyoto University, and written informed consent was obtained.

\section{Cognitive assessment}

Neuropsychologists administered the Scenery Picture Memory Test (SPMT) as part of a neuropsychological test battery that included the MMSE, Clock Drawing Test (CDT), Verbal Fluency Test (VFT) and Verbal Category Cued Memory test (CCMT), independently from the diagnostic assessments. For the CDT, the subject was asked to draw a clock with all the numbers on a blank piece of paper and indicate the time as 10 min after 11 o'clock. We used the 10-point scoring system by Rouleau et al. ${ }^{22}$ The CCMT, a modified version of Buschke's Double Memory Test reported previously, is a verbal memory test which contains 16 words from eight categories and uses category cues during encoding and recall. ${ }^{4,23}$ In the CCMT, only cued recall but not free recall is tested. The score is the number of items recalled correctly with the maximum score being $16 .{ }^{23}$ In VFT, the subject was instructed to name as many vegetables and sports as possible, each within $1 \mathrm{~min} .{ }^{23}$ The score was the total number of items mentioned in both categories.

The SPMT used a line drawing scenery picture (Fig. 1) of a living room in a house where 23 objects commonly observed in daily life are drawn on an A4 piece of paper: a telephone, a bookshelf, books, a table, chairs, two cups with saucers, a flower vase, a framed 


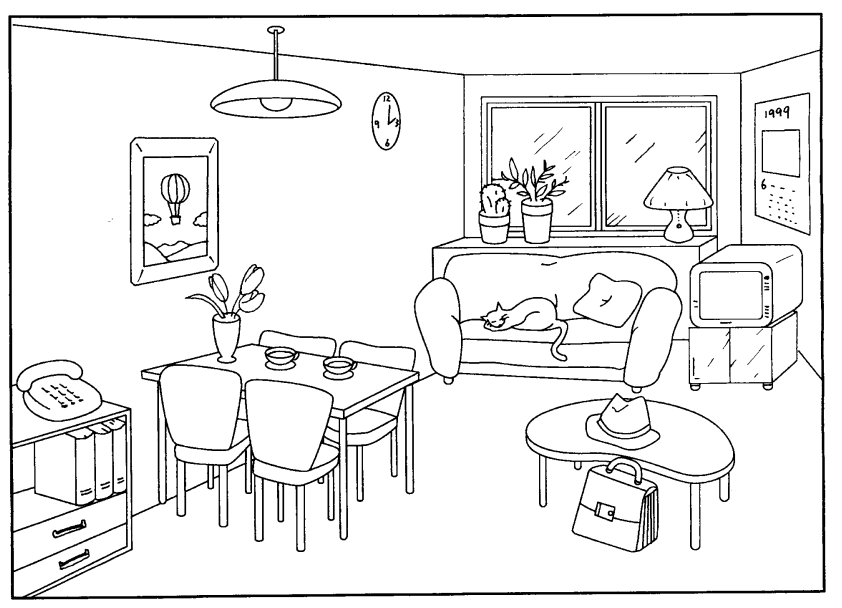

Figure 1 A line drawing scenery picture of a living room used in the Scenery Picture Memory Test.

picture on the wall, a clock, a ceiling lamp, a couch, a cushion, a cat, a low table, a hat on the table, a briefcase, a television, a desk for the television, a calendar on the wall, a flower pot with a cactus, a flower pot with a foliage plant, a table lamp and a window. We collected scores in two ways, which we call "Pict 1" and "Pict 2", respectively. In the first trial, Pict 1 , the examinee studies the picture for $1 \mathrm{~min}$ and is instructed to remember the items. After this encoding period, we distracted participants by asking them to conduct a brief digits forward test (four digit strings consisting of 4, 5, 6 and 7 digits, respectively). Participants were then asked to recall the objects in the picture without time limitation. This recall time usually takes less than $1 \mathrm{~min}$. The number of items recalled is the score for Pict 1 with no credit for duplicates.

In Pict 2, to enhance the encoding process, following the first trial, Pict 1, we asked participants to recall the locations of three specific items (telephone, hat and calendar), for example, "do you remember where the telephone was located in the picture?" After these questions, we presented the picture again and asked participants to name the items in the picture. Participants were asked to name at least 12 items. All participants in the current study could name at least 12 items. These tasks were not scored because our intention was to enhance memory by encouraging greater depth of processing. After this deep memory processing period, participants were distracted by the digits forward and backward subtest of the WAIS-R. ${ }^{24}$ Finally, they were asked again to recall the items in the picture. The number of the items recalled here was used as the score for Pict 2 . The mean approximate administration time of the SPMT is $2 \mathrm{~min}$ for Pict 1 and 6 min overall.

\section{Statistical analyses}

All data are presented as mean \pm standard deviation (SD). Student's t-tests were used to assess differences between group means on continuous variables. Pearson's $\chi^{2}$-tests were used to assess differences between groups on categorical variables. To measure the accuracy of the tests in discriminating between controls and patients, the area under the curve (AUC) of the receiveroperator curve (ROC) was assessed using the total sample as well as by two age groups ( $<75$ years vs $\geq 75$ years). Because controls in this study were younger and had higher education than AD patients in the total sample, we confirmed the validity of the SPMT in two age groups. We conducted the ROC analysis first using all $A D$ patients and controls, and second using only very mild AD patients (AD with MMSE $\geq 24$ ) and controls. Inter-rater and test-retest reliabilities were analyzed using the Spearman's rank correlation coefficient. The correlation between Pict 1 and Pict 2 was examined using Pearson's correlation coefficient. Test-retest and inter-rater reliabilities of SPMT were tested in the separate group of outpatients from a memory clinic. In this series of tests, two testers participated: one psychologist and one speech therapist. In both cases, two examinations were carried out at least 1 month apart; the average duration between test and retest was $2.3 \pm 1.5$ months, and the duration between inter-rater examinations was $2.8 \pm 2.1$ months.

\section{Results}

Demographic and basic neuropsychological characteristics of $\mathrm{AD}$ patients and controls are presented in Table 1 . In each age group ( $<75$ and $\geq 75$ years), there was no difference in age and education distributions between control and AD groups. The SPMT scores in patients and controls suggest no apparent ceiling and floor effects in either group (Fig. 2).

Sensitivity and specificity to detect AD cases by Pict 1 were $85.2 \%$ and $88.9 \%$ (cut-off $9 / 10$ ), respectively, and $84.4 \%$ and $90.7 \%$ (cut-off $12 / 13$ ) by Pict 2 , respectively. Positive and negative predictive values were $94.8 \%$ and $71.6 \%$ by Pict 1 , respectively, and $95.6 \%$ and $71.0 \%$ by Pict 2, respectively. Given the similar levels of sensitivity, the specificity of MMSE and CCMT were lower than those of the SPMT. Sensitivity and specificity by MMSE were $83.6 \%$ and $75.9 \%$ (cut-off $27 / 28$ ), respectively, and $81.3 \%$ and $81.5 \%$ (cut-off $7 / 8$ ) by CCMT, respectively. These results were almost the same for very mild $\mathrm{AD}$ cases (data not shown). Table 2 shows AUC of different tests. Among the total sample, the AUC of Pict 1 was significantly larger than those of MMSE, CDT and VFT. Among the younger age group ( $<75$ years), the AUC of Pict 1 was significantly larger than those of CDT and VFT. Among the older age group ( $\leq 75$ years), the AUC of Pict 1 was significantly larger than those of MMSE, CDR and VFT. The AUC of Pict 1 and Pict 2 were very similar among the total sample (Table 2, Fig. 3) as well as within each age group (Table 2). Pict 1 
Table 1 Characteristics of study participants

\begin{tabular}{|c|c|c|c|c|c|}
\hline & \multicolumn{2}{|c|}{ Control } & \multicolumn{2}{|c|}{$\mathrm{AD}$} & \multirow{2}{*}{$P$-value } \\
\hline & Average & SD & Average & SD & \\
\hline Both age groups & \multicolumn{2}{|c|}{$n=54$} & \multicolumn{2}{|c|}{$n=128$} & \\
\hline Age & 72.5 & 6.5 & 75.3 & 6.7 & 0.009 \\
\hline Education & 12.2 & 2.7 & 11.3 & 2.8 & 0.04 \\
\hline Female \% & \multicolumn{2}{|c|}{$46.3 \%$} & \multicolumn{2}{|c|}{$65.6 \%$} & 0.024 \\
\hline Pict 1 & 13.6 & 3.5 & 6.6 & 3.2 & $<0.001$ \\
\hline Pict 2 & 17.5 & 3.6 & 8.9 & 4.5 & $<0.001$ \\
\hline MMSE & 28.3 & 1.5 & 24.6 & 2.9 & $<0.001$ \\
\hline CDT & 9.6 & 0.8 & 9.0 & 1.5 & 0.004 \\
\hline CCMT & 10.3 & 2.4 & 5.1 & 2.6 & $<0.001$ \\
\hline VFT & 25.5 & 6.5 & 16.7 & 5.9 & $<0.001$ \\
\hline Age $<75$ years & \multicolumn{2}{|c|}{$n=39$} & \multicolumn{2}{|c|}{$n=51$} & \\
\hline Age & 69.2 & 3.3 & 69.0 & 4.7 & NS \\
\hline Education & 12.2 & 2.7 & 11.6 & 2.9 & NS \\
\hline Female \% & \multicolumn{2}{|c|}{$43.5 \%$} & \multicolumn{2}{|c|}{$66.7 \%$} & 0.034 \\
\hline Pict 1 & 13.8 & 3.7 & 7.5 & 3.1 & $<0.001$ \\
\hline Pict 2 & 17.7 & 3.6 & 10.0 & 4.2 & $<0.001$ \\
\hline MMSE & 28.5 & 1.3 & 25.0 & 2.7 & $<0.001$ \\
\hline CDT & 9.6 & 0.9 & 8.9 & 1.5 & 0.009 \\
\hline CCMT & 10.4 & 2.5 & 5.0 & 2.8 & $<0.001$ \\
\hline VFT & 33.5 & 10.4 & 19.8 & 12.2 & $<0.001$ \\
\hline Age $\geq 75$ years & \multicolumn{2}{|c|}{$n=15$} & \multicolumn{2}{|c|}{$n=77$} & \\
\hline Age & 81.1 & 4.5 & 79.5 & 3.9 & NS \\
\hline Education & 12.2 & 2.9 & 11.1 & 2.7 & NS \\
\hline Female \% & \multicolumn{2}{|c|}{$53.3 \%$} & \multicolumn{2}{|c|}{$64.9 \%$} & NS \\
\hline Pict 1 & 13.3 & 3.0 & 6.0 & 3.2 & $<0.001$ \\
\hline Pict 2 & 16.8 & 3.6 & 8.2 & 4.6 & $<0.001$ \\
\hline MMSE & 27.7 & 1.8 & 24.4 & 3.0 & $<0.001$ \\
\hline CDT & 9.7 & 0.8 & 9.1 & 1.4 & 0.124 \\
\hline CCMT & 10.1 & 2.2 & 5.1 & 2.5 & $<0.001$ \\
\hline VFT & 24.1 & 8.3 & 12.9 & 11.1 & $<0.001$ \\
\hline
\end{tabular}

AD, Alzheimer's disease; CCMT, Category Cued Memory Test; CDT, Clock Drawing Test; MMSE, Mini-Mental State Examination; NS, not significant; Pict 1 and Pict 2, Scenery Picture Memory Test 1 and 2; SD, standard deviation; VFT, Verbal Fluency Test (vegetables and sports/1 min each).

showed a larger AUC than CCMT in the overall sample and also in the older age group, although the difference was not statistically significant (Table 2, Fig. 3). The results of ROC analysis restricted to very mild patients remained the same as above.

In both Pict 1 and Pict 2 , comparison of the test-retest examination showed excellent correlations $(r=0.898$, $P<0.001$ for Pict $1 ; r=0.929, P<0.001$ for Pict 2). Inter-rater reliability was also high $(r=0.750, P<0.001$ for Pict $1 ; r=0.795, P<0.001$ for Pict 2).

Although the utility of Pict 1 and Pict 2 to detect AD is similar in terms of validity and reliability, to further examine the difference between shallow and deep encoding processes and a learning effect, we compared the result of Pict 1 with that of Pict 2 as a post-hoc analysis. In both control and $\mathrm{AD}$ groups, very high correlations between the two test scores were found (controls: $r=0.726, \quad P<0.001$; patients: $r=0.773$, $P<0.001)$. We examined the difference between Pict 2 and Pict 1 (i.e. Pict 2 - Pict 1) among patients and controls. The difference in scores was significantly larger among the control than the AD groups $(3.8 \pm 6.8$ vs $2.3 \pm 8.3, P<0.001)$.

\section{Discussion}

With ongoing advances in the treatment of $\mathrm{AD}$, early detection will become increasingly important for intervention, and counseling of patients and families. It would be highly beneficial for both patients and caregivers if the PCP could assess memory deficits in a simple and easy manner. In this study, we examined a new 
A

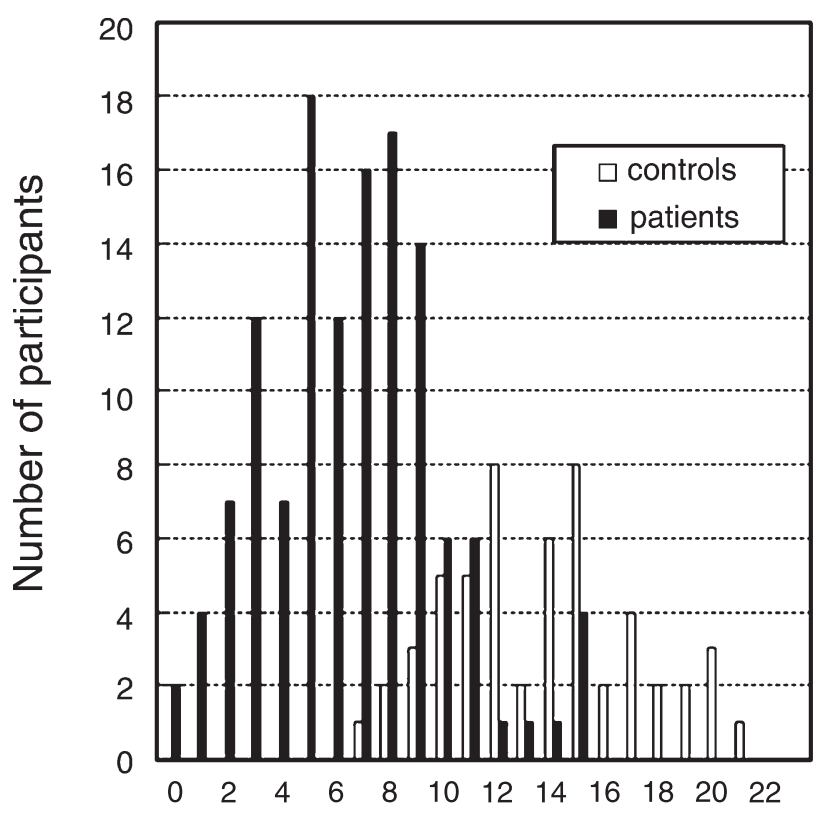

Number of items
B

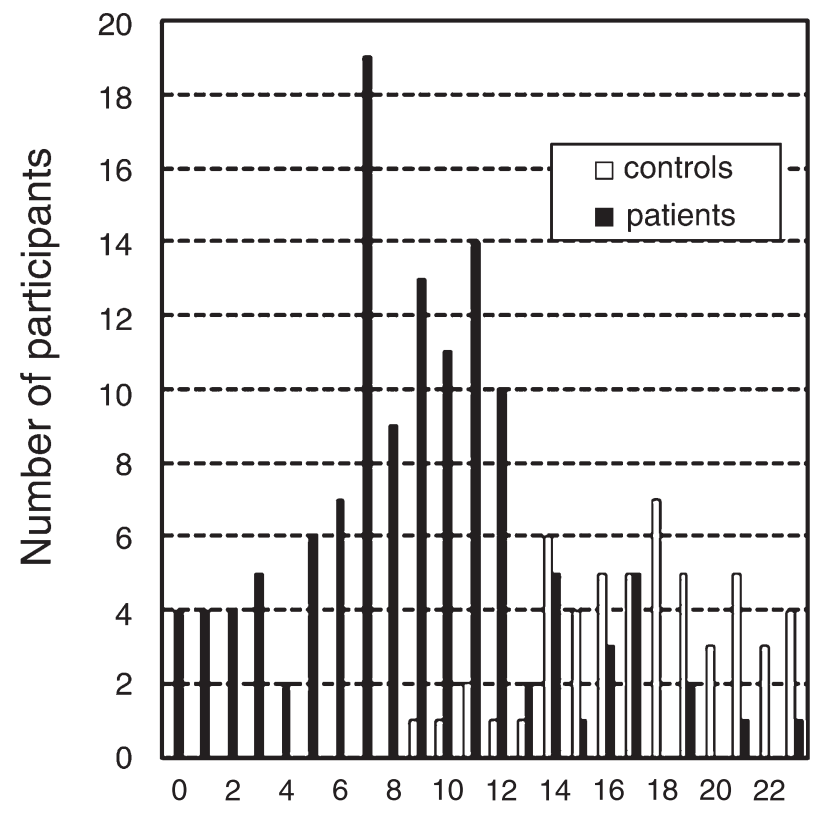

Number of items

Figure 2 Score distribution of Pict 1 (a) and Pict 2 (b). In (a) and (b), horizontal axes indicate the number of items in the picture reported by participants. Vertical axes indicate number of participants. Closed bars indicate results from Alzheimer's disease patients, and open bars from control participants.

Table 2 Area under the curves and the differences among tests

\begin{tabular}{|c|c|c|c|c|}
\hline & \multicolumn{2}{|c|}{ Control vs all AD } & \multicolumn{2}{|c|}{ Control vs very mild $\mathrm{AD}$} \\
\hline & AUC $(95 \%$ CI) & $P$-value & AUC (95\% CI) & $P$-value \\
\hline \multicolumn{5}{|c|}{ Both age groups } \\
\hline Pict 1 & $0.93(0.89-0.96)$ & Reference & $0.90(0.85-0.95)$ & Reference \\
\hline Pict 2 & $0.92(0.88-0.96)$ & NS & $0.89(0.84-0.94)$ & NS \\
\hline CCMT & $0.92(0.88-0.95)$ & NS & $0.89(0.84-0.94)$ & NS \\
\hline MMSE & $0.87(0.82-0.92)$ & 0.046 & $0.80(0.73-0.87)$ & 0.027 \\
\hline VFT & $0.82(0.76-0.88)$ & $<0.001$ & $0.76(0.68-0.83)$ & 0.001 \\
\hline $\mathrm{CDT}$ & $0.63(0.56-0.71)$ & $<0.001$ & $0.60(0.52-0.68)$ & $<0.001$ \\
\hline \multicolumn{5}{|c|}{ Age $<75$ years } \\
\hline Pict 1 & $0.90(0.84-0.96)$ & Reference & $0.88(0.80-0.95)$ & Reference \\
\hline Pict 2 & $0.90(0.84-0.96)$ & NS & $0.89(0.81-0.96)$ & NS \\
\hline СCMT & $0.91(0.86-0.96)$ & NS & $0.88(0.81-0.95)$ & NS \\
\hline MMSE & $0.89(0.82-0.95)$ & NS & $0.85(0.77-0.93)$ & NS \\
\hline VFT & $0.79(0.70-0.88)$ & 0.03 & $0.73(0.62-0.85)$ & 0.02 \\
\hline CDT & $0.65(0.55-0.75)$ & $<0.001$ & $0.61(0.51-0.72)$ & $<0.001$ \\
\hline \multicolumn{5}{|c|}{ Age $\geq 75$ years } \\
\hline Pict 1 & $0.95(0.90-0.99)$ & Reference & $0.92(0.86-0.99)$ & Reference \\
\hline Pict 2 & $0.92(0.87-0.98)$ & NS & $0.89(0.81-0.97)$ & NS \\
\hline CCMT & $0.92(0.87-0.98)$ & NS & $0.90(0.83-0.98)$ & NS \\
\hline MMSE & $0.82(0.72-0.92)$ & 0.023 & $0.70(0.54-0.86)$ & 0.014 \\
\hline VFT & $0.79(0.69-0.88)$ & 0.003 & $0.72(0.59-0.85)$ & 0.009 \\
\hline $\mathrm{CDT}$ & $0.64(0.52-0.76)$ & $<0.001$ & $0.60(0.47-0.73)$ & $<0.001$ \\
\hline
\end{tabular}

$P$-value indicates differences in area under the curve (AUC) compared with Pict 1. AD, Alzheimer's disease; CCMT, Category Cued Memory Test; CDT, Clock Drawing Test; MMSE, Mini-Mental State Examination; NS, not significant; Pict 1 and Pict 2, Scenery Picture Memory Test 1 and 2; VFT, verbal fluency (vegetables and sports/1 min each). 

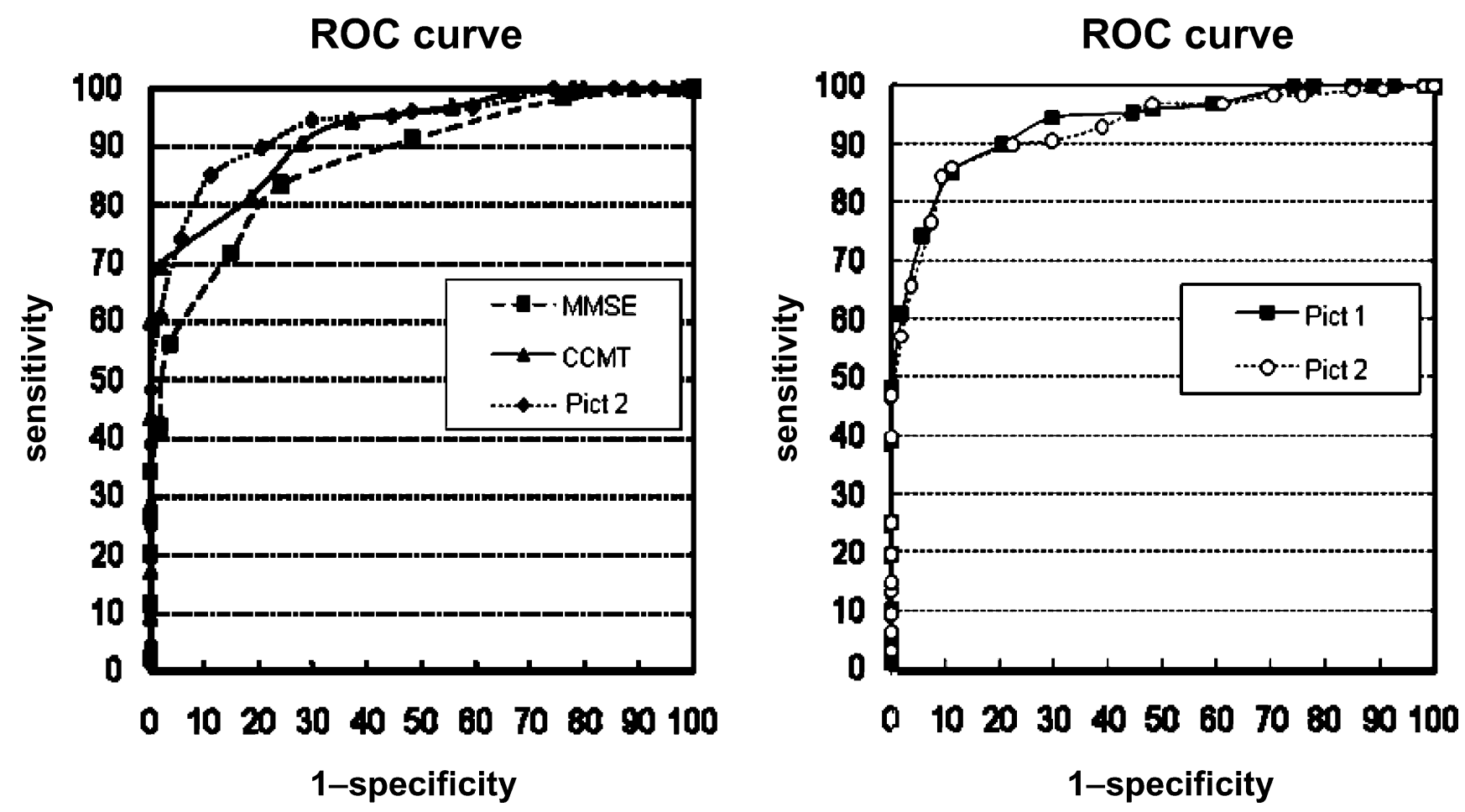

Figure 3 Receiver-operator curve (ROC) curves indicating results from control participants vs Alzheimer's disease (MMSE >19). MMSE, Mini-Mental State Examination; CCMT, Category Cued Memory Test; Pict 1, Scenery Picture Memory Test 1 ; Pict 2, Scenery Picture memory Test 2.

screening test, SPMT, to distinguish patients with early stages of $\mathrm{AD}$ from cognitively healthy elderly individuals. The SPMT had a larger AUC to identify even the very mild $A D$ cases (AD with MMSE $\geq 24$ ) compared with those of MMSE, VFT and CDT. The SPMT also demonstrated satisfactory test-retest and inter-rater reliabilities. Moreover, the test format was acceptable to elderly participants, without being intimidating or taxing.

There are several potential reasons for the high efficacy of this test in detecting early AD patients. First, pictorial material is usually easier to remember than materials presented by words, a phenomenon known as the "picture superiority effect". ${ }^{9,10,12,25}$ Superiority of memory for pictorial material over verbal material was often applied as a mnemonic aid for elderly. ${ }^{26,27}$ Potentially, the memory decline associated with normal cognitive aging could be ameliorated by the picture superiority effect, making it easier to distinguish $\mathrm{AD}$ patients from control participants.

Second, we used a picture of a living room with common furniture and objects familiar to most elderly. The scene may have multiple cues to enhance recall; each object in the scene becomes a cue for another object. In other words, once a part of the scene is recalled, other parts could be recalled because the scene is not unique but shares many common aspects of daily life. Categorically related or visually integrated cues are shown to be more effective in terms of encoding than unrelated or non-interacting cues. ${ }^{28}$ It has been also shown that the recognition of a scene as a context enhances memory of specific details. ${ }^{29,30}$ Buschke et al. reported in their case-control study that subjects free from dementia could encode and retrieve more effectively in the category cued recall memory tests than the demented. They suggested encoding specificity deficit in dementia patients. ${ }^{5}$ The multiple cues in the scenery picture in the SPMT may have resulted in facilitated encoding and retrieval of the items in the scene by the healthy elderly but not by $\mathrm{AD}$ patients, making it more effective in distinguish the two groups.

Additionally, in a recent functional imaging study, Gutches et al. reported that older adults compensate for their decrement of memory function in medial temporal lobe by activation of frontal systems, when pictorial materials are presented. ${ }^{31}$ Possibly, the pathological process of $\mathrm{AD}$ may hamper this compensatory function, resulting in the discrepancy in SPMT scores between the control and $\mathrm{AD}$ groups.

We examined the effect of shallow and deep memory processing on the performance of SPMT. Although the results showed more benefit for deep memory processing or a potential learning effect for cognitively normal elderly, Pict 1 and Pict 2 seem to be equivalent in the effectiveness of distinguishing $\mathrm{AD}$ 
patients from the controls. Because Pict 1 takes only 2 min to administer and has sufficient validity, Pict 1 may be more useful.

Limitations of the present study include the following. As mentioned above, because controls in this study were younger and had higher education than $\mathrm{AD}$ patients in the total sample, we confirmed the validity of the SPMT in two age groups. Further study in a large sample size would be required to generalize our results. Second, we tested in this study utility of the SPMT to distinguish early stage AD patients from controls. It would be important to further investigate how to use it in a PCP's office or a memory clinic, because other types of patients with memory deficit such as those with vascular dementia and depression may appear. Third, we used here only the CCMT to test specifically the memory domain of cognition. Although the CCMT is assumed to be an effective memory test as well as other standard memory tests such as the Logical Memory Subtest of the Wechsler Memory Scale - Revised or the California Verbal Learning Test, direct comparison of the SPMT with such memory tests would be required. ${ }^{32,33}$ Finally, AD patients who participated in this study came from outpatient referral to the memory clinic. These subjects might be different in various characteristics from those with $\mathrm{AD}$, but do not visit memory clinics. Therefore, the generalization of our results could be limited.

In conclusion, we present a new type of memory test which seems to be very useful in identifying early stage $\mathrm{AD}$ patients. The distribution of test scores had neither ceiling nor floor effects, and it was very easy to administer. We believe the scenery picture test will be a useful tool for routine clinical evaluations.

\section{Acknowledgments}

We thank Drs Judith A. Saxton, Mary Ganguli and Katherine Wild for their helpful suggestions. This paper was presented as a poster at the Mild Cognitive Impairment Symposium at Miami, Florida, March, 2007. This study was supported by grants from the Japan Ministry of Education, Culture, Sports, Science and Technology (no. 18590598) and National Institute on Aging in the United States (K01AG023014).

\section{References}

1 Ganguli M, Rodriguez E, Mulsant B et al. Detection and management of cognitive impairment in primary care: The Steel Valley Seniors Survey. J Am Geriatr Soc 2004; 52: 1668-1675.

2 Borson S, Scanlan JM, Watanabe J et al. Improving identification of cognitive impairment in primary care. Int $J$ Geriatr Psychiatry 2006; 21: 349-355.
3 Jitapunkul S, Chansirikanjana S, Thamarpirat J. Undiagnosed dementia and value of serial cognitive impairment screening in developing countries: a population-based study. Geriatr Gerontol Int 2009; 9: 47-53.

4 Petersen RC, Smith GE, Waring SC et al. Mild cognitive impairment: clinical characterization and outcome. Arch Neurol 1999; 56: 303-308.

5 Buschke H, Sliwinski MJ, Kuslansky G et al. Diagnosis of early dementia by the Double Memory Test: encoding specificity improves diagnostic sensitivity and specificity. Neurology 1997; 48: 989-997.

6 Solomon PR, Hirschoff A, Kelly B et al. A 7 minute neurocognitive screening battery highly sensitive to Alzheimer's disease. Arch Neurol 1998; 55: 349-355.

7 Buschke H, Kuslansky G, Katz M et al. Screening for dementia with the memory impairment screen. Neurology 1999; 52: 231-238.

8 Nasreddine ZS, Phillips NA, Bedirian V et al. The Montreal Cognitive Assessment, MoCA: a brief screening tool for mild cognitive impairment. J Am Geriatr Soc 2005; 53: 695-699.

9 Shepard RN. Recognition memory for words, sentences, and pictures. J Verbal Learn Verbal Behav 1967; 6: 156-163.

10 Nickerson RS. A note on long-term recognition memory for pictorial material. Psychon Sci 1968; 11: 58.

11 Hasher L, Zacks RT. Automatic and effortful processes in memory. J Exp Psychol 1979; 108: 356-388.

12 Park DC, Puglisi JT, Sovacool M. Memory for pictures, words, and spatial location in older adults: evidence for pictorial superiority. J Gerontol 1983; 38: 582-588.

13 Mayes AR. Learning and memory disorders and their assessment. Neuropsychologia 1986; 24: 25-39.

14 Benton AL. Revised Visual Retention Test, 4th edn. New York: Psychological Corporation, 1974.

15 Lezak MD. Neuropsychological Assessment, 3rd edn. New York: Oxford University Press, 1995.

16 Psychological Corporation. WAIS-III-WMS-III Technical Manual. San Antonio, TX: Psychological Corporation, 1997.

17 Doss RC, Chelune GJ, Naugle RI. WMS-III performance in epilepsy patients following temporal lobectomy. J Int Neuropsychol Soc 2004; 10: 173-179.

18 Gold JM, Poet MS, Wilk CM et al. The family pictures test as a measure of impaired feature binding in schizophrenia. J Clin Exp Neuropsychol 2004; 26: 511-520.

19 American Psychiatric Association. Diagnostic and Statistical Manual of Mental Disorders, 4th edn. Washington, DC: American Psychiatric Association, 1994.

20 McKhann G, Drachman D, Folstein M, Katzman R, Price D, Stadlan EM. Clinical diagnosis of Alzheimer's disease: report of the NINCDS-ADRDA Work Group under the auspices of Department of Health and Human Services Task Force on Alzheimer's Disease. Neurology 1984; 34: 939-944.

21 Folstein MF, Folstein SE, McHugh PR. "Mini-mental state". A practical method for grading the cognitive state of patients for the clinician. J Psychiatr Res 1975; 12: 189198.

22 Rouleau I, Salmon DP, Butters N et al. Quantitative and qualitative analyses of clock drawings in Alzheimer's and Huntington's disease. Brain Cogn 1992; 18: 70-87.

23 Funabiki Y, Takechi H, Akamatsu T et al. Development of a short neuropsychological battery to screen early dementia in elderly. Geriatr Gerontol Int 2002; 2: 179-186.

24 Wechsler D. WAIS-R Manual. New York: The Psychological Corporation, 1981. 
25 Paivio A, Csapo K. Picture superiority in free recall: imagery or dual encoding? Cogn Psychol 1973; 5: 176206.

26 Cavanaugh JC, Grady JG, Perlmutter M. Forgetting and use of memory aids in 20-70 year olds everyday life. Int J Aging Hum Dev 1983; 17: 113-122.

27 McDowd J, Botwinick J. Rote and gist memory in relation to type of information, sensory mode, and age. J Genet Psychol 1984; 145: 167-178.

28 Park DC, Smith AD, Morrell RW et al. Effects of contextual integration on recall of pictures by older adults. J Gerontol $1990 ; 45$.

29 Biederman I. Perceiving real-world scenes. Science 1972; 177: $77-80$.
30 Loftus GR, Bell SM. Two types of information in picture memory. J Exp Psychol 1975; 104: 103-113.

31 Gutchess AH, Welsh RC, Hedden T et al. Aging and the neural correlates of successful picture encoding: frontal activations compensate for decreased medial-temporal activity. J Cogn Neurosci 2005; 17: 84-96.

32 Psychological Corporation. Wechsler Memory Scale-Revised. San Antonio, TX: Psychological Corporation, 1987.

33 Delis DC, Kramer JH, Kaplan E, Ober BA. California Verbal Learning Test Manual.San Antonio, TX: Psychological Corporation, 1987. 